\title{
EL ROL DEL PODER JUDICIAL EN SU LUCHA CONTRA LA CORRUPCIÓN: EXTERNA EINTERNA*
}

\author{
Francisco Távara Córdova ${ }^{*}$
}

\begin{abstract}
Resumen:
El Poder Judicial constituye la principal institución Ilamada, dentro de un Estado Constitucional, a luchar contra la corrupción. Esto ciertamente, dentro de un marco de cooperación con otras instituciones.

Desde inicios del año dos mil uno, la legislación y acciones destinadas a revertir la corrupción judicial se han incrementado, destacando el rol de la judicatura a través de nuevos esquemas de actuación como el del sub sistema anticorrupción, cuya competencia ha sido ampliada, y asimismo el continuo y reconocido trabajo de la Oficina de Control de la Magistratura (OCMA).

La reforma judicial hoy en marcha en nuestro país plantea entonces que la lucha contra la corrupción pasa por fortalecer las instituciones existentes, a fin de consolidar en el Perú un sistema de justicia dotado de órganos imparciales, independientes, eficaces y eficientes. Para ello deberán ponerse en práctica un conjunto de acciones que han de desplegarse en conjunto con la promoción de algunos valores y de una ética pública en nuestra sociedad, los cuales, de la mano con una mayor transparencia, constituyan una auténtica política de prevención de la corrupción.
\end{abstract}

Palabras clave: Corrupción, transparencia, medidas preventivas, medidas sancionadoras.

A bstract:

The Judicial Power constitutes the main called institution within a Constitutional State, to fight against the corruption. This certainly, within a frame of cooperation with other institutions.

From beginnings of year two thousands one, the legislation and actions destined to revert the judicial corruption have been increased, emphasizing the roll of the judicature throughout new schemes of performance like the sub system of anticorruption, whose competition has been extended, and also the continuous and recognized work of the Office of Control of judges ( Oficina de Control de la Magistratura -OCMA).

The judicial reform been applied in our country points out that the fight against the corruption happens to fortify the existing institutions, in order to consolidate a system of justice equipped with impartial, independent,

\footnotetext{
* Se recoge aquí en líneas generales la ponencia presentada por el doctor Francisco Távara Córdova, Presidente del Poder Judicial, el 7 de noviembre de 2007, en la sede del Banco Mundial, ubicada en Washington, D. C. - Estados Unidos.

* Presidente del Poder Judicial 2007-2008.
} 
effective and efficient organs in Peru. To accomplish that purpose is necessary to put in practice a set of actions as well as the promotion of some values and a public ethics in our society, which, accompanied by a greater transparency, constitute an authentic policy of prevention of the corruption.

Key words: Corruption , Judicial Power, transparency.

\section{LA LUCHA CONTRA LA CORRUPCIÓN EN EL PERÚ}

\subsection{MARCO NORMATIVO}

Dentro de nuestro ordenamiento jurídico se precisa en el artículo 44ㅇ de la Constitución vigentequeel Estado tiene el deber degarantizar los derechos fundamentales de las personas, así como velar por la consolidación del sistema democrático. Por otro lado, es necesario recordar que el Perú ha suscrito la Convención Interamericana contra la Corrupción, aprobada mediante Resolución Legislativa № 26757.

M ediante esta Convención se compele a los Estados firmantes a crear «mecanismos necesarios para prevenir, detectar, sancionar y erradicar la corrupción» (Art. II.1 de la Conv.). Sin perjuicio de que nuestro país haya firmado dicha Convención, el principal hecho motor que ha movilizado al Perú a incrementar su legislación anticorrupción lo ha constituido su ingreso a partir del año 2001 a un régimen político distinto al dela década pasada.

Entrelas normas expedidas, podemos destacar las siguientes:

Medidas preventivas: cuyo objetivo es evitar que se produzcan actos de corrupción antes que penar su realización:

1. R.S. 160-01| -JUS del 11-04-01, que creó Ia Iniciativa Nacional Anticorrupción (INA).

2. D.S. 120-01-PCM del 17-11-01, que creó el Consejo Nacional Anticorrupción (CNA). Hay que precisar que con fecha 19 de octubre de 2007, se ha publicado el Decreto Supremo № 085-2007-PCM , quecrea la Oficina N acional Anticorrupción (ONA) que sustituiría a este Consejo.

3. Ley 26850 de Contrataciones y A dquisiciones del Estado (SEACE). 
4. Ley 27482 que regula la publicación de las declaraciones de ingresos y de bienes y rentas de los funcionarios y servidores del Estado.

5. Ley 27806 de Transparencia y de A cceso a la Información Pública

6. Ley 27815 de Código de Ética y su Reglamento.

7. Ley 28024 de Gestión de Intereses.

8. Ley deNepotismo.

9. Mecanismos de transparencia y participación ciudadana.

10. Creación de comisiones de ética y transparencia.

11. Creación del CERIAJUSy recomendaciones.

12. Medidas planteadas por la PCM.

13. Creación de FEDADOI (Decreto de urgencia 122-2001)

Medidas sancionatorias: Con las cuales se busca establecer sanciones a quienes ya lamentablemente incurrieron en casos de corrupción:

1. Creación dela Dirección de Policía contra la Corrupción, medianteR.M. 1000-2001-IN/ PN P.

2. Ley 27378 de Colaboración Eficaz.

3. Creación de seis juzgados y de seis sal as anticorrupción.

4. Creación de Procuradurías Públicas A nticorrupción Descentralizadas

5. Creación de seis fiscalías provinciales y seis superiores anticorrupción.

6. Instauración del Subsistema Anticorrupción.

7. Designación de un Procurador Ad Hoc para los casos de comisión de delitos presuntamente efectuados por el Ex Presidente Fujimori y su asesor Montesinos.

Asimismo, es de precisar que desde el año 2001 se han emitido un mayor número de normas de contenido penal destinadas a revertir el surgimiento de hechos de corrupción, entre las cuales se cuentan la Ley № 28755, que cambia la tipificación de los delitos de administración fraudulenta y otros; la Ley 27994, la cual modificó un conjunto de artículos del Código de Procedimientos Penales con el fin de abreviar el informe final del juez instructor; la Ley 28105, que buscaba ampliar de oficio el mandato de detención en los del itos de naturaleza compleja con más de diez inculpados; y la Ley 28117, de Celeridad y Eficacia Procesal.

También se ha modificado la legislación destinada a combatir el lavado de activos, adecuándola a situaciones no previstas, como las sucedidas durante la década pasada, de tal manera que evite sevuel van a repetir hechos detal al cance o contenido. ${ }^{2}$ 
Asimismo, instituciones como Defensoría del Pueblo tienen dentro de sus previsiones - según lo destacado en medios periodísticos - la creación de una unidad anticorrupción, cuyas facultades se encontrarán coordinadas con las de otras entidades.

Seaprecia pues queel desarrollo en el Perú de plenos esfuerzos por instaurar una democracia han traído como una de sus consecuencias el poner en práctica un cuadro normativo destinado a combatir la corrupción. Empero aún falta, consideramos, abordar líneas que aseguren la completa modernización y simplificación administrativa, la transparencia y ética pública, verdaderos pilares de una política de lucha contra la corrupción.

Dentro de esto, es necesario abordar aspectos esenciales como los siguientes:
a. Modernización de la Gestión Pública
b. Modernización y Fortalecimiento de los Entes Contralores del Estado
c. Reforma del Poder Judicial y a la N ormativa Legal Vigente
d. Transparencia en los Gobiernos Regionales y Municipales
e. Consolidación de la Participación Ciudadana

En referencia a estas dimensiones, es necesario abordar una decidida lucha en contra de la corrupción en nuestro país, no solo en el plano normativo, sino también en lo que respecta a estructuras estatales encaminadas a actuar positivamente en contra de la corrupción.

Incluso la lucha contra la corrupción ha de tener un matiz social. Como ha advertido el autor Enrique Bernales, si algo resalta en el Perú, es que «la corrupción siempre perteneció al ámbito del Derecho Penal bajo la forma de peculado. Nunca se analizó desde una perspectiva sociológica» ${ }^{3}$ BERN ALES, Enrique. La corrupción y la infinita descomposición. En:

Esto último resulta muy remarcable, como seanalizará más adelanteal hacer referencia a encuestas sobre la corrupción en el Perú.

\subsection{LA EXPERIENCIA PERUANA}

El año dos mil uno puso sobre la escena jurisdiccional una prueba sumamente ardua para el Poder Judicial peruano, en lo referido a su 
capacidad como organismo de control, y su directa vinculación con sus capacidades y posibilidades éticas, técnico-jurídicas y materiales, buscando así responder al desafío de coadyuvar en el tránsito de un régimen debilitado en su institucionalidad democrática a uno en el que se dediquen todos los esfuerzos por instaurar una democracia plena.

Al igual que otras naciones como Italia - donde se destaca el caso mani puliti - los jueces peruanos han participado y lo siguen haciendo en coadyuvar al tránsito o construcción de una democracia integral en el Perú.

Es la judicatura perteneciente al sub sistema anticorrupción la que tiene un papel central en esta tarea, la de juzgar los casos acaecidos durante la década pasada (habiéndose ya ampliado su competencia a hechos posteriores de corrupción), casos que valga destacar, han constituido formas graves de criminalidad, ciertamente inusitadas, dada su amplitud, su nivel intenso de inserción en el Estado, y su complejidad.

Y en estesentido conviene recordar pues lo expresado en los considerandos de la Resolución Administrativa № 024-2001-CT-PJ, del 31 deenero del año 2001, la misma que crea el subsistema anticorrupción, y que a lo postre refirió que «se ha generado, con motivo de estas investigaciones (seguidas en ese caso contra Vladimiro Montesinos y otros) una situación especial y de emergencia frente a la cual los mecanismos normales proveídos por las leyes orgánica del Poder Judicial y procesales respectivas, no tienen respuesta adecuada en razón de su carácter extraordinario».

Y es que, incluso, debe recordarse como estos casos de corrupción fueron calificados en su conjunto como generadores de una situación de «megacorrupción». Ello se explica porque los órganos anticorrupción conocen de un gran número de procesos, con una cantidad de encausados cuya cifra gira al rededor de 14924, suma que resulta a todas luces enorme.

Hasta el año 2006, el subsistema anticorrupción (creado en el año 2001) ha venido afrontando al rededor de 246 causas, de las cuales sólo una parte ha sido resuelta, existiendo todavía un amplio sector de procesos que aún se encuentra en trámite.

En el Poder Judicial del Perú somos conscientes deestos problemas, pero, al igual queen los procesos seguidos contra los casos deterrorismo, los jueces 
peruanos han demostrado que una preocupación capital debeser la deactuar con un escrupuloso respeto del debido proceso, a fin de que lo resuelto resista un examen de, por ejemplo, la jurisdicción internacional.

La resolución emitida por el Tribunal Supremo Chileno en el año dos mil siete, mediante la cual se pronunció favorablemente ante el pedido hecho por la CorteSuprema del Perú por la extradición del ex Presidente Alberto Fujimori Fujimori, es una muestra de quelos jueces y juezas del Perú vienen desplegando una labor imparcial e independiente, preocupada por garantizar el debido proceso legal de los sujetos encausados.

Y en lo que respecta al dinero que se ha logrado recuperar, gracias al Fondo Especial de Administración de Justicia del Dinero Obtenido Ilícitamente (FEDADOI), se tiene un monto de 183245307.38 nuevos soles. Esto a febrero de 2007, conforme a la información publicada en el Ministerio de Justicia. Esta cifra revela no solo la magnitud de la corrupción, pues lo que aquí se presenta resulta una parte de la misma, sino también los esfuerzos concretos que viene logrando la judicatura del subsistema anticorrupción.

A hora bien, resulta necesaria, dado aún el estado de cosas en el Perú, con permanentes e insistentes cuestionamientos al manejo dela cosa pública, el que se mantengan los órganos jurisdiccionales de la sub especialidad anticorrupción, tal vez ya como un sub sistema orgánico y permanente dela estructura judicial.

Tal subsistema anticorrupción, dotado de la estructura logística adecuada, tendría por competencia el conocer de aquellos delitos que impliquen corrupción pública. Independientemente de eventuales aportes y mejoras, considero queel lo corresponde plenamente con el requerimiento ciudadano por que el Poder Judicial demuestre tener un compromiso claro de luchar contra la corrupción.

Ciertamente, ese conjunto de órganos jurisdiccionales se insertaría dentro deun escenario de permanente coordinación inter institucional con oficinas de control de la administración pública, como la Contral oría General de la República, y el Ministerio Público, pues la política anticorrupción implica una labor conjunta de esa magnitud. 


\subsection{AVANCES Y RETROCESOS EN LA LUCHA CONTRA LA CORRUPCIÓN}

Debe tenerseen cuenta que una verdadera política anticorrupción pasa por involucrar y centralizar los esfuerzos y acciones de todas las instituciones vinculadas a la actividad de control. La política anticorrupción tiene pues que ser conjunta e integral.

Por otro lado, cuando hacemos referencia a una política integral, ésta ciertamente debe incorporar acciones orientadas tanto a modernizar las instituciones involucradas como a fortalecer los instrumentos para la sanción efectiva delos actos de corrupción.

Dentro de esteentendido, un papel sumamentevalioso en la lucha contra la corrupción lo tieneel fortalecimiento deaquellas instituciones cuya función esencial sea el control. Estamos hablando aquí del Poder Judicial, el Ministerio Público, la Policía Nacional, y, finalmente, de la Contraloría General de la República, cuya consagración constitucional se encuentra recogida en el artículo 82을 de nuestra Constitución Política.

Estas son las entidades que por excelencia están destinadas a fiscalizar, no solo los actos de privados, sino, con igual o mayor relieve, los actos del Estado en general, como por ejemplo, la sanción de aquellas conductas que configuren delitos contra la administración pública.

En este derrotero, se debe exigir que se ejecute el programa de reforma y financiamiento que sobre el particular fuera propuesto por la Comisión Especial de la Reforma Integral dela Administración de Justicia (CERIAJUS), y asimismo, con sus particularidades, las acciones destacadas al respecto por el Acuerdo Nacional por la Justicia. Sin duda, un poder que no se haya sujeto a control, dado el debilitamiento de las instituciones fiscalizadoras, da lugar a un campo abierto al ejercicio de la corrupción.

No debe entonces olvidarse que estamos ante un elemento fundamental del Estado de Derecho, pues «.... todo acrecentamiento - en palabras de JORGE REINALDO VANOSSI - del poder debe corresponder un vigorizamiento de Ios controles, acrecentamiento de las garantías, y un potenciamiento de las responsabilidades y esto vale para todo, para el sector público y para las grandes concentraciones de poder privado. A mayor poder, mayor control... $\rangle^{5}$ 
Bajo esta óptica es entendible la creación de una Oficina Nacional A nticorrupción (ONA) destinada, como organismo público, a la lucha exclusiva contra la posi ble comisión deactos de corrupción. Sin embargo, la creación de esta entidad ad hoc, demanda pues, sin quitar con ello los fines valiosos que persigue, queel actual gobierno especifique cuál sería su margen deacción antelas demás instituciones de control, como la Contraloría General de la República, el Poder Judicial o el Ministerio Público.

Y es que considero que una verdadera lucha anticorrupción pasa por fortalecer las instituciones que, dentro de la estructura institucional de nuestro Estado, están convocadas a desplegar esta tarea. Ellas son, como ya había adelantado el Poder Judicial, el Ministerio Público, la Contraloría General de la República y la Policía Nacional.

Es por ello que implica un retroceso en esta labor el que no se desplieguen mayores recursos para la plena implementación del Nuevo Código Procesal Penal, I a cual por el contrario, ha visto postergada su vigencia en las ciudades de Lima y Callao. Es de destacar que una reforma procesal penal destinada a asegurar la celeridad y eficiencia de los procesos penales, constituye un pilar básico de la lucha contra la corrupción.

Es indispensable entonces que un Estado que reclama haber asumido un compromiso serio en su lucha contra la corrupción, despliegue todas las acciones necesarias para el fortalecimiento de importantes instituciones de control (como por ejemplo, el del Poder Judicial), y sin duda, la implementación de una nueva normatividad procesal penal.

Hay que destacar que de los resultad os arrojados por la encuesta aplicada por el Instituto de Opinión Pública dela Pontificia Universidad Católica del Perú (PUCP), setiene quetres decada cuatro peruanos piensa que su prójimo peruano es básicamente deshonesto. Y sorprende aún más cuando esto es contrastado con la encuesta de PROÉTICA, organización especializada en tema corrupción en mi país, querevela que «el $82 \%$ dela población manifestó ser alta o medianamente tolerante frente a la corrupción»6.

Sin duda revertir un Estado social como el descrito en el Perú, exige un compromiso político sumamentefirme, en coordinación con la sociedad civil, pues la «participación de la sociedad civil más voluntad política es la ecuación que funciona» ${ }^{7}$ en la lucha contra la corrupción. 
Pero también es deprecisar que, conformeala misma encuesta dela Pontificia Universidad Católica del Perú, la opinión pública concibequetanto el Poder Judicial (15\%) junto a la ciudadanía (15\%), esto es, en la misma intensidad, están obligadas a luchar contra la corrupción.

Empero, esta misma encuesta arroja que el $73 \%$ de la ciudadanía nunca ha denunciado actos decorrupción. Esto, entreotras razones «porqueconsidera que es inútil y una pérdida de tiempo, por temor a represalias, por no saber donde acudir o que podía hacerlo, o porque no existen incentivos para denunciar» ${ }^{8}$

Y tal panorama es sumamente grave, pues no hay que olvidar que la labor de el checks and balances implica no sólo un «monitoreo y control permanente entre las diversas instituciones públicas, sino, también entre la sociedad y el Estado»`. La ciudadanía tiene entonces una enormeresponsabilidad frente a la fiscalización y control de la actuación pública.

Deestemodo, la actuación del Estado debe ser firme, en especial en el plano educativo, de tal modo que la necesaria siembra de valores y principios morales constituya una prioridad dentro de la agenda pública, pues, de persistir tal estado, es la propia democracia, como régimen capaz de garantizar la institucional idad, la eficiencia y los derechos fundamentales, la que se pondría en entredicho.

En el Poder Judicial peruano, como más adelante se destacará, somos conscientes de ello, y aún cuando no tengamos influencia en la determinación de la política educativa del Estado, se ha emprendido, con optimismo, una campaña de valores, que busca transformar la actitud del usuario del servicio de justicia, frente al Poder Judicial, a fin de que la entienda como una institución independiente e imparcial .

Y esto porquela «democracia como un derecho personal y social, como una forma degobierno, como un modo de vida, es una cultura anticorrupción» ${ }^{10}$

\section{LA ÉTICA PÚBLICA COMO POLÍTICA DE PREVENCIÓN DE LA CORRUPCIÓN}

Como ha escrito acertadamente Efrén Chávez Hernández, «la integridad pública es el mejor instrumento de lucha contra la corrupción ${ }^{11}$. Esta idea 
de cultura ética ha sido expresamente asumida por la Ley del Código de Ética de la Función Pública, al señalarse en su inciso 1) del artículo go que: «...la cultura de probidad, transparencia, justicia y servicio público establecida en el presente Código...».

Sin perjuicio de lo anotado se debe destacar quesi bien la Ley del Código de Ética de la Función Pública no exige que cada entidad expida un Código de Ética, sin embargo, la instauración detal es conjuntos normativos, al interior de cada entidad pública, implica un componente importante dentro de la promoción de la ética pública, pues ello ayuda a concientizar a cada servidor y funcionario público respecto de sus deberes y los fines de la institución.

No obstante, no se ha de perder de vista que cada entidad se haya obligada, en virtud de la citada Ley, a instaurar los mecanismos y procedimientos necesarios para la eficacia del referido Código, ya que el mismo contiene una serie de prescripciones imperativas; y un régimen de sanciones, que van desde la amonestación hasta la destitución.

Es claro entonces que para promover la cultura ética de una institución concreta, sea un Ministerio, un organismo regulador, o un Municipio, se requiere codificar los valores y principios ad hoc que han de asegurar la excelencia institucional, teniendo ciertamente a la vista el cuadro valorativo general que establecela ley en referencia. Por eso el legislador, en el inciso 2) de su artículo 9o de la Ley estudiada, ha dispuesto que «...El Órgano de la Alta Dirección establece los mecanismos e incentivos que permitan una actuación correcta, transparentey leal de los servidores públicos....».

Esto evidencia que estamos en la actualidad ante un fenómeno de «juridización» dela ética pública, pues, y anteel crecimiento dela corrupción en los ámbitos de la vida pública, se recurra a crear «oficinas de ética» y sancionar «códigos de ética» ${ }^{12}$.

El sancionar dichas normas particulares, constituye un modo de promover la ética dela función pública, deahí quela propia Ley ha mencionado, en su inciso 2) de su artículo 9o, que es obligación de la Alta Dirección de cada entidad pública:

$\ll \ldots$

a. Difundir el Código de Ética de la Función Pública. 
b. Diseñar, establecer, aplicar y difundir los incentivos y estímulos a los servidores públicos que cumplan con los principios, deberes y obligaciones del presente Código y respeten sus prohibiciones.

c. Desarrollar campañas educativas sobre las sanciones para los servidores públicos que tengan prácticas contrarias a los principios establecidos en el presenteCódigo.

..》

Este precepto prescribe además que, en caso de no haberse aprobado un Código de Ética particular para cada institución, ello no exime de promover la ética pública institucional, ya que existe el Código deÉtica de la Función Pública, sancionado mediante Ley.

De otro lado, un rol importante en la promoción de la ética pública lo tiene sin duda al guna la educación, la que ha de comprender el estudio de los hábitos éticos, desde los primeros años de la escuela, hasta los años universitarios. N o se puede entender la formación de una conciencia ética solo al interior de cada entidad, como si el personal del mismo viviera aislado dela sociedad. En este aspecto, se requiere una promoción integral, que incida en la vida educativa de los ciudadanos, a fin pues de que los mismos tomen conciencia del rol de la ética pública, de sus efectos y al cances.

Desde esta dimensión, no hay mejor política preventiva de la corrupción que la adopción de una intensa ética pública al interior de cada entidad estatal.

\section{LA TRANSPARENCIA PÚBLICA COMO COMPONENTE DE UNA POLÍTICA ANTICORRUPCIÓN}

La corrupción ha existido desde la A ntigüedad, pero con el desarrollo de las comunicaciones se ha dado a conocer más en los años recientes ${ }^{13}$. Esto implica una apuesta por la mayor visi bi lidad de los actos del Estado, lo cual significa someter al ente público al análisis y escrutinio de la sociedad.

Gomes Filho ha sostenido por ello que dar transparencia a una relación de poder significa promover su reequilibrio, ya sea porque hace que el poder se transformeal someterse a la crítica, al escrutinio público y, por consiguiente, 
al control social; o porque la transparencia invita a las personas envueltas en el ejercicio de poder a asumir una posición activa de protagonistas ${ }^{14}$.

Coincido entonces con el ya mencionado Gomes Filho cuando anota que la transparencia es, de hecho, un recurso clave para que la ciudadanía pueda desarrollar una influencia directa sobre la administración pública, demodo de compensar las asimetrías de poder en la formación de las decisiones públicas y en la generación de bienes y servicios públicos ${ }^{15}$.

Por otro lado, de la corrupción se ha dicho que «es como un hongo que en la oscuridad crece y se reproduce mejor». De este modo, a la corrupción se contrapone la transparencia. Incluso en Teoría Política se llega a hablar, como lo hace el iusfilosofo italiano Luigi Ferrajoli, de visibilidad de los actos del Estado ${ }^{16}$. Consecuentemente, transparencia, visibilidad, publicidad, convergen en forma decisiva para asegurar un sano manejo del Estado, a fin de que la ciudadanía pueda tener conocimiento y control delos actos vinculados a la marcha del Gobierno.

Deahí entonces queKant juzgase un principio capital el dela transparencia. A notó el filósofo alemán que «la prohibición de la publicidad, incluso la mera limitación es el mayor daño que se le puede hacer a un pueblo» ${ }^{17}$.

Sin duda, contribuye a lo dicho el que se asegure una mayor transparencia de los funcionarios con mayor poder de decisión dentro del ente público. Coadyuva a esta imagen de credibilidad el quelos altos funcionarios públicos no tengan el derecho al secreto bancario ni a la reserva tributaria. Ello aparecesin duda como una medida extrema, pero antela urgencia del riesgo de una grave deslegitimación del Estado, resulta más pertinente un tipo de medida que provoque a la ciudadanía la impresión de una decidida lucha contra la corrupción.

En el Poder Judicial peruano hemos asumido Ia transparencia como una línea central dentro de la reforma judicial. En este entendido si bien a la fecha se ha instituido una nueva página web del Poder Judicial, sustentada en los criterios de facilidad, eficiencia y transparencia, buscando así beneficiar a los usuarios del servicio judicial, todavía se requiere hacer muchas mejoras en estas materias.

Es en este carril que se quiere poner en funcionamiento un Portal Web del Poder Judicial: esto es, un entorno informático que permita a los usuarios 
interactuar con los componentes web, de tal modo queya podría ser en este escenario el óptimo para desarrollar mejoras como la instauración plena de notificaciones judiciales vía internet, u ofrecer mayor información de los expedientes a través de este portal web.

Ello no sólo aseguraría eficacia a las labores de impartición dejusticia, sino también una mayor transparencia sobre el funcionamiento institucional y administrativo del Poder Judicial.

En este sentido, es de precisar que se ha dad o un carácter gratuito al sistema de consulta web del estado de los procesos judiciales, a fin de facilitar la tutela jurisdiccional brindada a los usuarios del servicio de justicia. Para ello, esta medida se apoya en la principal herramienta degestión informática del Poder Judicial, y que a la fecha sólo funciona en un todavía número reducido deórganos jurisdiccionales del país: merefiero al Sistema Integrado deJusticia(SIJ), el cual permite una gestión informática del Despacho judicial. Ahora bien, es una meta, con apoyo de la Cooperación Internacional, el ampliarla a todas las sedes jurisdiccionales del Perú. De ahí que se haya adquirido en el año 2007 un gran número de computadoras (cuatro mil) de última generación para tal objetivo.

Se tiene previsto asimismo continuar con el plan de publicación de las resoluciones expedidas por la Corte Suprema de Justicia en la página web del Poder Judicial, debiendo destacarseademásqueel Consejo Ejecutivo denuestra institución ha aprobado se procedan a publicar también allí las resoluciones que expidan las Salas y Juzgados de las diversas Cortes Superiores. Ello constituye, en el plano jurisdiccional, una muestra innegable de transparencia. La transparencia en lajurisprudencia por parte dela CorteSuprema sesostiene en un A cuerdo de Sala Plena de Tribunal Supremo para tal fin, el mismo que fue adoptado el 17 de enero de 2007. Es decir, fue el máximo órgano de deliberación del Poder quien asumió el reto de la transparencia judicial.

Debemos recordar también que el Poder Judicial peruano ha recibido en el año dos mil siete un importante premio por parte de la A sociación Ciudadanos al Día (CAD) en mérito a su actuación destinada a asegurar una mayor transparencia en esta materia. Y que en este mismo carril, la reciente compra efectuada por el Poder Judicial de al rededor de cuatro mil computadores, se ha hecho bajo el mayor clima de transparencia posible, habiéndose invitado para ello a variados colectivos de la sociedad civil. 
Incluso esta adquisición de equipos de cómputo fue destinada no solo a proveer demayor celeridad a las actuaciones del Poder Judicial, sino también, de mayor transparencia, dado que estos ordenadores permiten la implementación del Sistema Integrado Judicial (SIJ) en todas Ias dependencias jurisdiccionales del país.

\section{EL PODER JUDICIAL COMO INSTITUCIÓN DE CONTROL DE LA CORRUPCIÓN.}

Somos conscientes de que la percepción asentada en importantes sectores de la ciudadanía, mediante la cual se considera al Estad o como una entidad invadida por la corrupción, resulta sumamente contraproducente para el fortalecimiento democrático e institucional del país, pues la corrupción le deslegitima.

Como bien anota Jorge Valdez, «en la era de los medios de comunicación, las percepciones adquieren con frecuencia mayor importancia quela propia realidad $\gg{ }^{18}$. Y dentro de este entendido, la reciente encuesta real izada por la Universidad de Lima, y publicada el 27 de octubre del año en curso en el diario El Comercio revela que la desconfianza en el Poder Judicial bordea el $39.2 \%$, mientras que un 56.3\% confía poco en nuestra institución.

De esto se tiene un peligroso dato, y es sin duda, que estos índices de confianza ciudadana ponen en cuestionamiento la propia legitimidad social del Poder Judicial. Empero, hay que advertir que de los encuestados, un $76.4 \%$ dice nunca haber litigado, y sólo responden que sí un $23.6 \%$. Esto es, un gran número de los encuestad os emite su punto de vista negativo sobre el Poder Judicial sin nunca haber tenido una experiencia directa en un proceso jurisdiccional.

Esto nos lleva a la conclusión de que esa percepción negativa sobre en el Poder Judicial, se debe por lo menos en parte a cómo la imagen de nuestra institución es tratada en al gunos medios de comunicación, imagen que por cierto en mucho resulta negativa, dado que son importantes los espacios noticiosos que ocupan las intervenciones de la Oficina de Control de la Magistratura respecto de un hecho de corrupción, sin que lamentablemente esa prensa muchas veces no destaquen aquella otra dimensión que revela estos hechos: y es de que el control judicial esta allí, operativo, tanto en su dimensión preventiva como ex post. 
Sin duda, una tarea de reconciliación del Poder Judicial peruano con la sociedad pasa pues no sólo desplegar acciones para revertir la comisión de actos de corrupción, sino, asimismo, ampliar los lazos de comunicación, y transparencia con la sociedad, como se viene haciendo a la fecha durante esta gestión.

Pero, asimismo, ha de recordarse que el año 1992, fecha en la quese produjo una ruptura del orden constitucional del país, una enorme cantidad de magistrados, de todos los grados judiciales, fueron retirados de sus cargos mediante los siguientes Decretos Leyes siguientes: № 25423, № 25425, № 25442 , № 25443 , № 25446 , № 25471 , № 25492 , № 25529 , № 25563 , № 25580 y № 26118.

Incluso es de señalar que, y medianteel Decreto Ley №25441, seestableció la conformación transitoria de la Corte Suprema de la República, en tanto culminara el proceso de ratificación judicial extraordinario y se efectúe el nombramiento de magistrados. De otro lado, a través del Decreto Ley № 25424 se cesó a los miembros del Consejo N acional de la M agistratura.

Este cese masivo de magistrados, además de la suspensión delas funciones del Consejo de la Magistratura como organismo de nombramiento de magistrados en junio del año 2000, esto hace no más de siete años, la Comisión Interamericana de Derechos H umanos se pronunciase señal ando que «tras ocho años de intervención ejecutiva en el Poder Judicial, más del $80 \%$ de los jueces y fiscales del país revisten status «provisional», advirtiendo además que la falta de garantías de inamovilidad ha hecho a los jueces vulnerables a manipulaciones del Poder Ejecutivo» ${ }^{19}$.

Consecuencia de ello es que aún hoy nuestro Poder Judicial, se encuentra todavía recuperando su plena institucionalidad, contando para el mejor desarrollo de este proceso con la designación de magistrados titulares, por parte del Consejo Nacional de la Magistratura, luego de que nuestra institución judicial ha operado con altos niveles de provisionalidad y suplencia durantelargo tiempo.

Y es que ha de destacarse quefrentea los Poderes y organismos del Estado, es el Poder Judicial el Ilamado a hacer efectiva la vinculación de éstos al ordenamiento jurídico vigente, esto es, a una ordenación y sometimiento a límites precisos en el ejercicio de sus funciones. En ese mismo sentido, el 
Poder Judicial al someter a los entes públicos al Derecho, evita o controla los actos de corrupción.

Y es que dentro de la teoría dela separación defunciones «el Poder Judicial juega un papel decisivo en el equilibrio de poderes, su fortaleza no radica, en el sentido más estricto, en la representatividad social, sino del derecho; digamos que somete el poder a la fuerza del derecho, se convierte en un contrapoder pal pable y eficaz»²0.

Como ha opinado M cllwain, «la única institución esencial para defender el Derecho siempre ha sido y todavía es un Poder Judicial honesto, hábil, preparado e independiente» ${ }^{21}$. La judicatura ordinaria se constituye así en una auténtica garantía jurisdiccional del régimen democrático y de los derechos fundamentales. Pero nada de ello es posible de no realizarse un ejercicio jurisdiccional independiente, y asimismo imparcial.

No le falta razón por ello al constitucional ista Enrique Bernales Ballesteros al afirmar que la corrupción ha sido provocada en el Perú en mucho por el «mal funcionamiento del Estado y la fal ta desistemas de control y vigilancia efectivos», y en esteentendido «por el predominio de regímenes autoritarios y la frágil institucional idad democráti ca» ${ }^{22}$.

De estemodo, un Poder Judicial fortal ecido, y en este entendido, integrado por jueces independientes e imparciales, aparece como una efectiva garantía no sólo de la democracia, sino también del real control de las actuaciones públicas, y con ello, dela prevención y sanción de los actos de corrupción.

\section{LA POLÍTICA ANTICORRUPCIÓN DENTRO DE LA REFORMA JUDICIAL}

Conformea una encuesta real izada por A poyo Opinión y M ercado S.A ${ }^{23}$., la sociedad peruana considera que sólo tres de cada diez peruanos son honestos; $y$, del mismo modo, si ete de cada diez estarían dispuestos a pagar una coima para ganar un proceso judicial.

Existe, en estesentido, un elemento casi endémico y estructural, denominado habitualmente corrupción, el cual no solamente se encuentra inserto en el Poder Judicial, sino en la sociedad peruana en general. 
Pero si bien no se debe caer en el extremismo de abstraer el tema de la corrupción judicial, y achacarla a la entidad total de la nación peruana, sí sedebeimputarsecierta corresponsabilidad delo quelamentablementeviene sucediendo a las Facultades de Derecho, a los Colegios de A bogados y al mismo Poder Judicial.

A las primeras porque, en su labor de formación de nuevos abogados, debieran otorgar un rol importante a la dimensión ética de los futuros profesionales del Derecho, cosa que lamentablementeno ocurreen algunos casos.

Por otro lado, y en lo referentea los Col egios de Abogados, estos deben dejar de ser entidades pasivas, y asumir un rol activo en el ejercicio de sus facultades disciplinarias, pues, como se ha destacado en un reciente estudio del sociólogo LuisPásara, al cual cito en términos textuales, pareciera existir:

«...Carencia devoluntad de investigar y sancionar (...) Dificultades para que los casos denunciados sean admitidos, demora en el procedimiento, renuencia a usar procedimientos y pruebas de oficio, y criterios confusos o contradictorios para determinar la existencia de faltas a la ética profesional contribuyen a un bajo nivel de sanción. Como se ha indicado, sobre el total de casos denunciados durante 2003, hasta marzo de 2005 sólo en $8.94 \%$ había recaído una sanción....».

Estos datos se encuentran solamente referidos al Colegio de A bogados de Lima, hacia donde se dirigió la muestra en la cual se ha basado el estudio del autor citado. Convieneentonces que se promueva otro estudio similar, en el cual se explore la realidad de los Colegios de A bogados de provincias sobreel particular. En cualquier caso, me permito sugerir que en lo referido a la lucha contra la corrupción, los Col egios de A bogados deben sumar a su rol crítico, un papel dinámico, colaborando así de manera decidida en la lucha contra la corrupción.

Ahora bien, la lucha contra la corrupción en el ámbito judicial, requiere también contar con el respaldo de un control preventivo. Estoy convencido de ello, y en ese sentido, he considerado siempre que resulta necesario que la judicatura realice un sacrificio en este extremo, vinculado a que no al cancen a los funcionarios judicial es al egaciones a la tutela de derechos a 
la reserva tributaria y al secreto bancario frente a las labores fiscalizadoras emprendidas por el órgano de control institucional.

Dicho órgano de control tendría, en el conocimiento del flujo patrimonial del magistrado o servidor judicial, los más certeros medios para detectar alguna irregularidad de parte de los miembros del Poder Judicial. Esto significa contar con un sistema riguroso no sólo de auditoría contable, sino también informática, ya que la corrupción siempre tiende a adoptar formas cada vez más difíciles de detectar.

A este respecto, destáquese que en enero del año dos mil siete se presentó una iniciativa de Ley, aprobada por la Sala Plena de la Corte Suprema de Justicia, para reconocer a la J efatura de OCM A la facultad para limitar los derechos al secreto bancario, reserva tributaria y secreto de las comunicaciones, siempre que mediase un procedimiento disciplinario en curso. El Congreso dela República no ha tenido todavía un pronunciamiento con respecto a esa iniciativa.

Del mismo modo, ha de afirmarse enfáticamente que no solo basta con proponer el traslado del control disciplinario a un órgano externo y plurirrepresentativo, como lo es el Consejo Nacional de la Magistratura, para creer que con ello el problema quedará resuelto.

Es más, y sobre la misma pertinencia deestetipo de propuestas, bien debería tenerse presente que ya hoy el Consejo $\mathrm{N}$ acional de la Magistratura tiene facultades disci plinarias respecto de los miembros del Poder Judicial, pero que, frente a ello, corresponde a la misma ciudadanía determinar si esa importante institución ha podido hoy satisfacer las demandas de la población, del mismo Poder Judicial y de los diferentes medios de comunicación social al respecto.

Por otro lado, aquella frase trillada de que «Otorongo no come a otorongo», resulta insuficiente y hasta injusta en el caso del Poder Judicial, si se toma en cuenta la labor de una Oficina deControl que vienecon esfuerzo obtenido valiosos resultados.

Debe además tenerse presente como el Consejo N acional dela M agistratura ha rechazado varias de las propuestas de destitución de jueces que habían sido formuladas por el mismo Poder Judicial. 
Tampoco conviene olvidar que las estadísticas miden más bien la percepción subjetiva de la población; y además que, por lo menos en muchos casos, la Ilamada corrupción judicial resulta para al gunos abogados la mejor excusa para justificar su derrota en un proceso judicial, derrota que ha sido consecuencia de su negl igencia, o sencillamenteresultado lógico de no haber tenido el derecho que invocaban.

Teniendo presentetodo lo expuesto, desdeel mismo Poder Judicial peruano vienen impulsándose una serie de acciones destinadas a fortalecer sus labores de control interno, destacando entre ellas el que se haya instaurado una Comisión encargada de elaborar el nuevo Proyecto del Reglamento de Organización y Funciones de la Oficina de Control de la Magistratura, adecuando ciertamente dicha norma a los al cances de Ley 28149, Ley que incluye la participación de la sociedad en los órganos de control del Poder Judicial y el Ministerio Público.

Y es queconstituyeuna prioridad para el Poder Judicial peruano la develar por la plena implementación de la referida ley, a fin de que se introduzcan en la labor de control elementos de fiscalización externa sobre el comportamiento funcional de los (as) diferentes jueces (zas) y fiscales del Perú.

Asimismo, se considera adecuado dentro de estelineamiento de trabajo, el interconectar, a través de un sistema deinformación, a la Oficina de Control de la Magistratura (OCMA) con Ias Oficinas descentralizadas de control existentes en diversos distritos judicial es del país, a fin de fortal ecer así sus actividades de control ${ }^{24}$.

En síntesis, y sin duda alguna, el Estado tiene un rol de suma gravedad frente al estado dela corrupción en el Perú. Sin embargo, sólo a través dela asunción de una conciencia ética por parte de cada individuo, es posible revertir de manera total la corrupción. Corresponde al juez y al ciudadano enfrentar la corrupción como servidores dela ética pública, y con ello, delos valores considerados como los más relevantes dentro de una sociedad determinada, salvo mejor parecer. 
Francisco A. Távara Córdova - El Rol del Poder Judicial en su lucha contra la corrupción: externa e interna

1 Dicho cuadro normativo ha sido obtenido del Plan Nacional de Lucha Contra la Corrupción y Ética Ciudadana. En: http:/ / www.minjus.gob.pe/ cna/ Info_CNA/ Archivo\%20del\%20Plan.pdf. Revisado con fecha 28 de octubre de 2007.

2 Prado Saldarriaga, Víctor. La corrupción y el lavado de activos: el caso de las personas expuestas políticamente. Exposición real izada con fecha 29 deoctubre de 2007 en el Salón de Juramentos del Palacio deJusticia.

3 Bernales, Enrique. La corrupción y la infinita descomposición. En: http:/ / palestra.pucp.edu.pe/ index.php?id=154. Revisad o con fecha 28 de octubre de 2007.

4 Cifra obtenida de: http:/ / www.idl.org.pe/ idlrev/ revistas/ 172/ Siles.pdf Revisada el 28 Oct 2007.

5 Vanossi, J orge Reinaldo. La corrupción como desviación patológica contraria a la ética pública. (p. 546). Especial de la Revista Jurídica de Buenos Aires: Derecho Administrativo y A portes para el Rediseño Institucional de la República. REIRIZ, María Graciela (Coordinadora). Facultad de Derecho de la Universidad de Buenos Aires. 2004.

6 Ugaz, José. Hay un anhelo expreso de limpiar la política de corrupción. En: Estado de la opinión pública: corrupción. Lima. PUCP. A ñoll, Junio de2007. pág. 7.

7 Patrón, Pepi. Carecemos de voluntad política para luchar contra la corrupción. En: Op. Cit. pág. 10.

8 A bad, Samuel. El difícil camino para enfrentar la corrupción. . En: Op. Cit. pág. 15.

9 Meini, Iván. Mientras las personas utilicen mecanismos alternativos e ilegales para satisfacer sus necesidades, la educación en valores y princi pios será insuficiente. En: Op. Cit.. pág. 19.

10 Vega Carreazo, Rudecindo. Corrupción estructural. Una aproximación diferente. En: http:/ / palestra.pucp.edu.pe/ pal_est/ ?file=anticorrupcion/vega.htm. Revisado con fecha 28 de octubre de 2007

11 Chávez Hernández, Efrén. Ética en el Poder Legislativo. En: Boletín M exicano de Derecho Comparado. Número 115 Enero-A bril 2006. pág. 10.

12 Ibid.

13 Ibid. Loc. Cit.

${ }^{14}$ Citado por: Cunill Grau, Nuria. La Transparencia en la Gestión Pública ¿Cómo construirle viabilidad? (pág. 25). En: Transparencia en la Gestión Pública. I deas y Experiencias para su viabilidad. Guatemala. INDES. 2006

15 Citado por: Cunill Grau, Nuria. Op. Cit. pág. 28

16 El jurista italiano refiere que: «la corrupción significa un doble Estado y, como fenómeno estructural, comporta la lesión de todos Ios principios democráticos: Ia publicidad, la transparencia, la responsabilidad, la visibilidad del poder». En: Entrevista a Luigi Ferrajoli. Isonomía № 09. Octubre de 1998. pág. 191

17 Citado por Simón G, JoséLuis. Sin justicia y con prensa amenazada. En: http:/ / www.pulso.org/ Espanol/ Archivo/ simon.htm\#simon. Revisado con fecha 17 de enero de 2008.

18 Valdez, Jorge. Seguridad Pública en el Espacio Sudamericano: Narcotráfico, Lavado de Dinero y Corrupción. En: http:/ / pal estra.pucp.edu.pe/ index.php?id=165\&num=2. Revisado con fecha 28 deoctubre de 2007

19 Lovatón Palacios, David. Cambios en la Justicia Peruana y Sociedad Civil (1990-2002) Informe para Ia Fundación Ford. IDL. Mayo 2002. pág.27

20 Delgado Carrillo, Fortino. El Equilibrio de Poderes. En: Valadez, Diego y Gutierrez Rivas, Rodrigo. Democracia y Gobernabilidad. Memoria del IV Congreso Nacional de Derecho Constitucional. T. II. UNAM, México, 2001. pág. 207.

${ }^{21}$ Citado por: Carbonell, Miguel y Salazar, Pedro. . División de Poderes y Régimen Presidencial en México. UNAM, M éxico, 2006, pág. 14.

22 Citado por Gamarra Herrera, Ronald. FUEGO CRUZADO SOBRE EL SISTEMA ANTICORRUPCIÓN. En: http:/ / www.justiciaviva.org.pe/ justiciamail/ jm0262.htm obtenida el 28 Oct 2007

${ }_{23}$ Hecha para el Instituto de Defensa Legal (IDL) en noviembre de 2005.

24 Bases para el Plan Decenal de Reforma y Modernización del Poder Judicial al año 2017. Pág. 12 